\title{
COVID-19 in a child with severe aplastic anemia
}

\author{
Yunus Akçabelen ${ }^{1}$, Ayça Koca Yozgat ${ }^{1}$, Aslinur Ozkaya-Parlakay ${ }^{1}$, and Nese Yarali ${ }^{1}$ \\ ${ }^{1}$ Ministry of Health Ankara City Hospital
}

May 11, 2020

\section{COVID-19 in a child with severe aplastic anemia}

Yunus Murat Akçabelen ${ }^{1}$, Ayça Koca Yozgat ${ }^{1}$, Aslı Nur Parlakay ${ }^{2}$, Nese Yarali ${ }^{1}$

${ }^{1}$ Department of Pediatric Hematology, Ankara City Hospital Children's Hospital, Turkiye

${ }^{2}$ Department of Pediatric Infectious Disease, Ankara City Hospital Children's Hospital, Turkiye

Article type: Letter to the editör

Running Title: COVID-19 in pediatric aplastic anemia

Key words: COVID-19, children, aplastic anemia

Disclosures: none

Word counts: 625

\begin{tabular}{ll}
\hline Abbreviations & Abbreviations \\
\hline SARS-CoV-2 & Severe acute respiratory syndrome coronavirus 2 \\
WHO & World Health Organization \\
QRT-PCR & Quantitative real-time reverse transcription polymerase chain reaction \\
\hline
\end{tabular}

Corresponding author:

Ayça Koca Yozgat, MD, Pediatric Hematology Department, Ankara City Hospital, Ankara, Tel.: 03125526000, Email: draycayozgat@yahoo.com, ORCID: 0000-0001-6690-721X

Severe acute respiratory syndrome coronavirus 2 (SARS-CoV-2) is a type of coronavirus first isolated in December 2019 in Wuhan, China. World Health Organization (WHO) has described SARS-CoV-2 as a pandemic on March 11, 2020. ${ }^{1}$ As of early May 2020, more than 3 million infected patients and more than 200 thousand deaths have been reported globally. ${ }^{2}$ It is evident that people of any age can contract the virus and the underlying medical condition is the main determinant for the severity of the disease. ${ }^{3}$ However, since the beginning of the outbreak, there is paucity of data on the course of disease in children with primary or acquired immunodeficiency. ${ }^{4-9}$ To our knowledge, there is no report, in English literature, describing a child with aplastic anemia and COVID-19. In this report, we describe a child with aplastic anemia affected with COVID-19.

A 14-year-old boy, who has been followed-up with a diagnosis of severe aplastic anemia at our hematology department and not currently receiving active treatment for aplastic anemia, presented with fever, sore throat and epistaxis for two days. He had had a history of exposure with a person suspected to have COVID-19. At admission, his body temperature was $38.5^{\circ} \mathrm{C}$ and hyperemia of the oropharynx was noted. He had no 
tachypnea, dyspnea; no rales or rhonchi were heard on auscultation of the lungs. His oxygen saturation was normal $(>95 \%)$ in room air. Complete blood count revealed a white blood cell count of $1.70 \times 10^{9} / \mathrm{L}$, absolute neutrophil count of $0.19 \times 10^{9} / \mathrm{L}$, absolute lymphocyte count of $1.40 \times 10^{9} / \mathrm{L}$, absolute monocyte count of $0.06 \times 10^{9} / \mathrm{L}$, hemoglobin of $8.3 \mathrm{~g} / \mathrm{dL}$, and platelet count of $12 \times 10^{9} / \mathrm{L}$. C-reactive protein level was $0.00221 \mathrm{~g} / \mathrm{L}$. The anteroposterior chest radiograph revealed bilateral minimal paracardiac infiltration. High resolution computed tomography of the chest revealed no abnormality including infiltration, consolidation or ground-glass opacities. Febrile neutropenia treatment with cefepime was started and platelet suspension was transfused. Test for SARS-CoV-2 by quantitative real-time reverse transcription polymerase chain reaction (QRT-PCR) from combined nasal and oropharyngeal swab specimen was positive. On follow up, his body temperature normalized after the second day of hospitalization. His condition never worsened and oxygen saturation never decreased. Regular erythrocyte and platelet transfusion program were continued. On followup, no microorganism was isolated in peripheral blood cultures. Following twice negative repeat QRT-PCR testing, the patient was discharged on the 15th day of hospitalization in good condition.

Cases of COVID-19 in age $<20$ years comprise around $2 \%$ of the infected population and mortality in this age group is very rare. ${ }^{4-6}$ There is an inverse relationship with the age of the child and severity of the disease, ${ }^{6}$ the reason(s) of which are still not established.

Unlike older age and co-morbidities including, diabetes, hypertension, obesity and smoking, there is paucity of data on the impact of immunosuppression, as a risk factor, on the prognosis of COVID-19. ${ }^{10}$ Filocamo et al. reported that children treated with immunosuppressive drugs for rheumatologic disorders do not have an increased risk of respiratory or life-threatening complications of COVID-19 compared with the general population. ${ }^{11}$ In a systematic review, 110 immunosuppressed patients were reported to have an overall better outcome when compared with other comorbidities. ${ }^{12}$ One may speculate that immunocompromised state, per se, might be a favorable factor to limit the inflammatory reaction which commonly accompanies the moderate/severe disease and is the contributor for such better prognosis. Such a speculation is contrary to the general opinion that immunocompromised state increases infection risk, but, indeed, is paradoxically protective. ${ }^{10,12,13}$

In our patient, we speculate that both younger age and the immunocompromised state are the two contributing factors for the very mild disease. However, further reports with larger sample sizes are warranted to delineate the impact of immunocompromised states on the prognosis of children affected with COVID-19.

\section{References}

1. World Health Organization. WHO Director-General's opening remarks at the media briefing on COVID-19 - 11 March 2020. March 11, 2020.

2. World Health Organization. Coronavirus disease (COVID-19) outbreak. Available at: https://www.who.int/emergencies/diseases/novel-coronavirus-2019.[Accessed: 03.05.2020]

3. Preliminary Estimates of the Prevalence of Selected Underlying Health Conditions Among Patients with Coronavirus Disease 2019 - United States, February 12-March 28, 2020. MMWR Morb Mortal Wkly Rep. ePub: 31 March 2020.

4. Wu Z, McGoogan JM. Characteristics of and important lessons from the coronavirus disease 2019 (COVID-19) outbreak in China: summary of a report of 72,314 cases from the Chinese Center for Disease Control and Prevention. JAMA . 2020 [Epub ahead of print]

5. Lu X, Zhang L, Du H, Zhang J, Li YY, Qu J, Chinese Pediatric Novel Coronavirus Study Team, et al. SARS-CoV-2 infection in children. $N$ Engl $J$ Med . 2020. [Epub ahead of print]

6. Dong Y, Mo X, Hu Y, Qi X, Jiang F, Jiang Z, et al. Epidemiological characteristics of 2143 pediatric patients with 2019 coronavirus disease in China. Pediatrics . 2020. [Epub ahead of print]

7. Yu J, Ouyang W, Chua MLK, Xie C. SARS-CoV-2 Transmission in Patients With Cancer at a Tertiary Care Hospital in Wuhan, China. JAMA Oncol. March 25, 2020. [Epub ahead of print] 
8. Hrusak O, Kalina T, Wolf J, Balduzzi A, Provenzi M et al. Flash survey on severe acute respiratory syndrome coronavirus-2 infections in paediatric patients on anticancer treatment. Eur $J$ Cancer . 2020;132:11-16.

9. Sieni E, Pegoraro F, Casini T et al. Favourable outcome of Coronavirus-19 in a 1-year-old girl with acute myeloid leukaemia and severe treatment-induced immunosuppression. Br J Haematol . 2020. [Epub ahead of print]

10. D'Antiga L. Coronaviruses and immunosuppressed patients. The facts during the third epidemic. Liver Transpl . 2020. [Epub ahead of print]

11. Filocamo G, Minoia F, Carbogno S et al. Absence of severe complications from SARS-CoV-2 infection in children with rheumatic diseases treated with biologic drugs. J Rheumatology. Apr 2020. [Epub ahead of print]

12. Minotti C, Tirelli F, Barbieri E, Giaquinto C, Donà D. How is immunosuppressive status affecting children and adults in SARS-CoV-2 infection? A systematic review. 2020 Apr 23. J Infect . 2020; S0163-4453(20)30237-1.

13. Balduzzi, A., Brivio, E., Rovelli, A. et al. Lessons after the early management of the COVID-19 outbreak in a pediatric transplant and hemato-oncology center embedded within a COVID-19 dedicated hospital in Lombardia, Italy. Estote parati . Bone Marrow Transplant . (2020). [Epub ahead of print] 